\title{
The Effects of Various Improvement Methods Applications on Herbage Yield of Natural Pastures
}

\author{
Ayşe Çalık ${ }^{1, a, *}$, Tahir Polat ${ }^{1, b}$ \\ ${ }^{1}$ Department of Field Crops, Faculty of Agriculture, Harran University, 63000 Şanluurfa, Turkey.
} *Corresponding author

\begin{tabular}{l|l}
\hline A R T I C L E I N F O & A B S T R A C T \\
\hline Research Article & $\begin{array}{l}\text { In this study, which was performed on an over-grazing pasture in Şanliurfa under the influence of a } \\
\text { dry climate, the effects of different breeding methods such as natural(control), fertilization, } \\
\text { insemination, fertilization+insemination+insemination+insemination + release on natural pastures } \\
\text { were investigated. In order to increase the yield potential of Natural Pastures in the research area, } \\
\text { manure, seedling, fertilization+seedling, fertilization+seedling+version methods were applied on } \\
\text { both protected and grazing fields. Using the transect method, key plant species in the region were } \\
\text { determined. As a result of the research, according to two-year averages, the highest dry grass yield } \\
\text { in grazing area was } 47.98 \mathrm{~kg} / \mathrm{da} \text { fertilized seedlings and the lowest yield was 21.40 kg/da natural } \\
\text { (control) seedlings. According to two-year averages, the highest dry grass yield in the protected area } \\
\text { was obtained from } 171.29 \mathrm{~kg} / \mathrm{da} \text { manure, and the lowest value was obtained from } 82.77 \mathrm{~kg} / \mathrm{da} \text { natural } \\
\text { (control) pasture. According to the results of breeding methods applied in the field of research; in } \\
\text { accepted : } 17 / 08 / 2019 \\
\text { adition to protecting pasture areas, a suitable fertilization is required. In addition, it was concluded } \\
\text { that the desired result could be achieved by making a regular grazing according to the rules of grazing } \\
\text { amanjman. }\end{array}$ \\
$\begin{array}{l}\text { Keywords: } \\
\text { Breeding } \\
\text { Dry grass } \\
\text { Fertilization } \\
\text { Yield } \\
\text { Seedling }\end{array}$
\end{tabular}

Türk Tarım - Gıda Bilim ve Teknoloji Dergisi 7(10): 1714-1721, 2019

\section{Doğal Meralarda Uygulanan Değişik Islah Metotlarının Kuru Ot Verimi Üzerine Etkileri}

\begin{tabular}{|c|c|}
\hline M A K A L E B İ L G İ S İ & Ö Z \\
\hline $\begin{array}{l}\text { Anahtar Kelimeler: } \\
\text { Gübreleme } \\
\text { Kuru ot } \\
\text { Mera 1slahı } \\
\text { Verim } \\
\text { Üsten tohumlama }\end{array}$ & 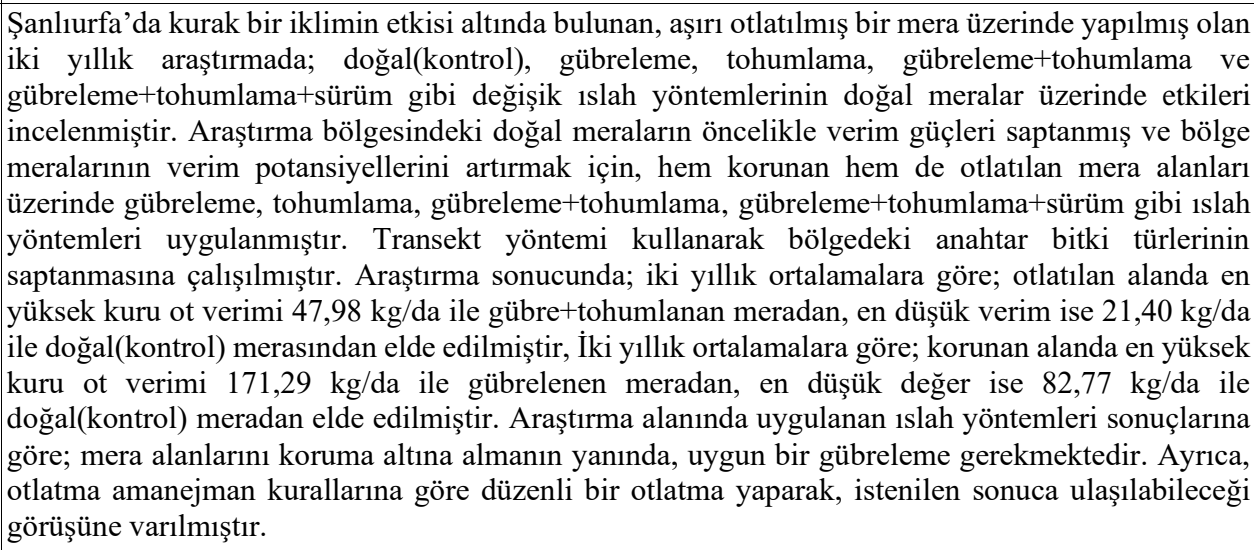 \\
\hline
\end{tabular}




\section{Giriş}

Ülkemizde doğal çayır-meralarımız yıllardan beri süre gelen bilinçsiz ve her türlü teknikten uzak bir kullanım sonucu, kötü duruma gelmiştir. Sürdürülebilir tarımsal üretimin ana unsurlarından birinin yem bitkileri yetiştiriciliği olması nedeniyle özellikle hayvanlar için kaliteli yem üretmek, çayır ve meraların erken ve aşırı derece otlatılmasını önleyebilmek için, tarla tarımı içerisinde yem bitkileri üretim alanlarının arttırılması zorunlu hale gelmiştir (Çalık, 2018). Ülkemiz ve bölgemiz çayır-meralarının bugün içinde bulunduğu kötü durum; hayvancılığımızı ve dolayısıyla da gelişme çabası içinde bulunan ülkemizin ekonomisini olumsuz yönde etkilediği gibi, en önemli doğal kaynaklarımız olan toprak ve su kaynaklarımızın da zarar görmesine yol açmaktadır. Bu sorunları çözerek doğal çayır-meralarımızın ıslah edilerek yeniden bol ve kaliteli yem üretir duruma getirilmeleri, ülkemizin kalkınma çabalarına büyük katkı sağlayacaktır (Hatipoğlu, 1987). Ülkemiz ve bölgemiz hayvancılığı genelde, çayır ve meralara dayanmaktadır. Ülkemiz hayvancilığında besiciliğin yeteri kadar gelişmemiş olması sebebiyle hayvanlar çayır-meraya dayalı olarak beslenmekte veya hayvanların beslenmesinde kullanılan kesif yemlerin yeterli kalitede olmaması nedeniyle hayvansal ürünlerde de kalite düşmektedir. Bu nedenle besin değeri yüksek yem bitkileriyle dengeli bir şekilde beslenen hayvanlarımızdan, yüksek ve kaliteli verim alınması için gereken yapılmalıdır (Çalık, 2018).

Bölgede yapılan araştırmalar bugün mera olarak kullanılan alanlarının kuru ot verimlerinin bölgelere göre değişmek üzere 30-90 kg/da, bitkiyle kaplı alan yüzdelerinin ise \%10-27 arasında değiştiğini göstermiştir
(Bakır, 1976). Bazı bölgelerimizde ise mera olarak; üzerinde hemen hiç bitki örtüsü bulunmayan, erozyon yarıntıları, taşlık ve çıplak kayalardan oluşan alanlar kalmıştır (Elçi, 1980). Bölgedeki çayır meralar 3.296,405 hektarlık alanından, 1.263,00 hektarı çayır, geriye kalan 3.283,775 hektarı da meradır (Bakır, 1981).

Çalışmada otlatmanın etkisiyle kaybolmaya yüz tutmuş bitki türlerinin saptanması, bu türlerin mera örtüsündeki payları, bu bileşim içerisinde gösterdikleri değişmelerin incelenmesi ve otlatılan mera alanları üzerinde uygulanan değişik 1slah yöntemlerinden hangisinin bölgemize en uygun olduğu saptanmıştır. Şanlıurfa'da mera vejetasyonunun özellikleri ve uygulanan değişik ıslah yöntemlerinden elde edilen verim sonuçlarının saptanması ile, ileride daha geniş alanlarda uygulamaya konulabilecek mera amenajman ve islahı programlarına fayda sağlayacaktır.

\section{Materyal ve Yöntem}

Şanlıurfa bölgesi doğal mera alanlarında yürütülen çalışma, tesadüf parselleri deneme desenine göre üç tekrarlamalı olarak kurulmuştur. Her bir parsel büyüklüğü yaklaşık 20 dekar olarak alınmıştır. Deneme alanın toprak yapıs1 bitki besin maddelerinden potayumca zengin ve fosforca fakirdir. Organik madde bakımından ise orta düzeydedir. Çizelge 1'den görüldüğü gibi uzun yıllar ortalamasına göre Şanlıurfa'nın nisbi nem oranı \%49, yıllık ortalama sıcaklığı $18,2^{\circ} \mathrm{C}$, yıllık toplam yağışı 463 mm'dir. Ocak ayı en serin, Temmuz ise en yüksek sıcaklıkların oluştuğu aylardır.

Çizelge 1 Şanlıurfa'nın Uzun Yıllar Ortalaması Bazı Önemli İklim Değerleri (Anonim, 1998)

Table 1 Sanliurfa's Long-term Average Some Important Climate Values (Anonymous, 1998)

\begin{tabular}{l|ccccc}
\hline \multicolumn{1}{c}{ Aylar } & Mak. Sic. $\left({ }^{\circ} \mathrm{C}\right)$ & Min. Sic. $\left({ }^{\circ} \mathrm{C}\right)$ & Ort. Sic. $\left({ }^{\circ} \mathrm{C}\right)$ & Ort. Yağ 1 Ş $(\mathrm{mm})$ & Nisbi Nem $(\%)$ \\
\hline Ocak & 21,6 & $-10,6$ & 5,1 & 93,1 & 71,0 \\
Şubat & 22,7 & $-12,6$ & 6,7 & 70,2 & 68 \\
Mart & 29,0 & $-7,3$ & 10,3 & 66,2 & 61 \\
Nisan & 33,9 & $-3,2$ & 15,8 & 52,0 & 55 \\
Mayis & 40,0 & 2,5 & 21,8 & 26,0 & 44 \\
Haziran & 42,7 & 8,3 & 27,7 & 2,6 & 31 \\
Temmuz & 46,5 & 15,0 & 33,3 & 0,6 & 28 \\
Ağustos & 46,2 & 15,5 & 31,1 & 0,6 & 30 \\
Eylül & 41,7 & 0,0 & 26,7 & 1,0 & 43 \\
Ekim & 37,8 & 1,9 & 19,9 & 25,0 & 58 \\
Kasım & 33,6 & -6 & 12,8 & 43,0 & 69 \\
Aralık & 29,0 & $-6,4$ & 7,3 & 82,4 & \\
\hline
\end{tabular}

Sicaklık: 59 Yıllık, Nisbi Nem: 58 Yı1lık, Yağış: 59 Yıllık

Denemede, korunulan ve otlatılan alanlarda farklı 1slah yönteminin etkileri araştırılmıştır. Denemede hem korunan hem otlatılan alanda uygulanan yöntemler: 1) doğal mera (kontrol) 2) gübreleme 3) tohumlama 4) gübreleme +tohumlama 5) gübreleme +tohumlama +sürüm biçiminde belirlenmiştir. $\mathrm{Bu}$ yöntemlerin meranın verim ve botanik bileşimi üzerindeki etkileri incelenmiştir. Deneme süresince $10 \mathrm{~kg} \mathrm{~N} / \mathrm{da}$ (Üre formunda) ve $5 \mathrm{~kg}$ P2O5/da dozları öngörülmüştür, ilk yıl fosforlu gübrenin tamamı ve azotlu gübrenin $1 / 2$ 'si sonbaharda uygulanmıştır. İlkbahar başında ise geri kalan azotlu gübrenin tamamı verilmiştir.
İkinci yılda aynı gübre dozları uygulanmış, fosforlu gübrelerin tamam1, azotlu gübrelerin $1 / 2$ 'si sonbaharda, geri kalan azotlu gübrenin tamamı ilkbahar başında uygulanmıştır.

Araştırmada, korunan ve otlatılan mera alanları üzerindeki parsellere üsten tohumlama yapılmıştır, Üsten tohumlamadaki karışımlar için yedi tür önerilmiştir. Bu türler Onobrychis sativa (\% 25), Medicago sativa (\% 15), Lolium perenne (\% 10), Festuca rubra (\% 10), Festuca ovina (\% 10), Agropyron cristatum (\% 15), Poa pratensis (\% 15)'dır, Dekara atılacak tohumluk miktarının hesaplanmasında; 


$$
\mathrm{KGTM}=\frac{\mathrm{YTM} \times \mathrm{KKP}}{\mathrm{KD}}
$$

KGTM : Karışıma girecek tohumluk miktarı

YTM : Yalın Tohumluk Miktarı ( $\mathrm{kg} / \mathrm{da})$

KKP : Karışıma Katılma Payı ( \% )

KD : Kullanma Değeri

formülü kullanılmıştır (Gençkan, 1985).

Mera araştırma alanı yer yer ana kaya ve çok az bir toprak profiline sahip olmasından dolayı toprağ devirerek değil, çizerek işleyen diskaro aleti kullanılmıştır. Bu araştırmada, meranın kuru ot verimi, Transekt yöntemine göre; mera durumu saptanmıştır.

Çizelge 2'de görüldüğü gibi araştırmanın birinci yılında Ekim, Aralık ve Nisan ayları dışında ortalama sıcaklıklar ikinci yıla göre daha yüksek olmuştur.

\section{Transekt Yöntemi}

$\mathrm{Bu}$ yöntemde $100 \mathrm{~cm}$ uzunluğunda $1 \mathrm{~cm}$ genişliğinde bir alan incelenmiştir, Dolayısıyla incelenen alan her transekt için $100 \mathrm{~cm}^{2}$ lik bir saha oluşturulacaktır. $\mathrm{Bu}$ amaçla da yaklaşık $100 \mathrm{~cm}$ uzunluğunda bir transekt çubuğu kullanılmıştır. Çubuğun bir ucu vejetasyon içerisine kolayca girebilmesi için sivriltilmiştir.

Transekt çubuğu boyunca $1 \mathrm{~cm}$ 'lik şeridin incelenmesi için özel bir ölçme çubuğu kullanılmıştır, Çubuğun ilerlemesi sırasında $100 \mathrm{~cm}^{2}$ 'lik alan içerisinde kalan bitkiler her $1 \mathrm{~cm}^{2}$ 'de işaretlenmiştir. Eğer $1 \mathrm{~cm}^{2}$ 'de iki bitki türü görülmüşse, bunlardan daha iyi gelişmiş olanı alınmıştır. Korunan alanda, seçilen 3 parselin her birinden 10 tane transekt ünitesi incelenmiştir. Transektler 20 dönümlük parseller üzerinden alınmıştır. Şanlıurfa ili, Fatik doğal meralarının bitki örtüsü yapısını belirlemek için, kantitatif karakterlere dayalı bir vejetasyon etüdü yapılmıştır. $\mathrm{Bu}$ vejetasyondaki bitki örtüsü incelenirken, transekt yönteminin (Conard, 1957) tarafından geliştirilen vejetasyon ölçüm yöntemi kullanılmıştır.

Çizelge 2 Şanlıurfa'da 1998-1999 ve 1999-2000 yıllarının bazı önemli iklim değerleri (Anonim, 1998-2000)

Table 2 Some important climate values of Şanliurfa between 1998-1999 and 1999-2000 (Anonymous, 1998-2000)

\begin{tabular}{|c|c|c|c|c|c|}
\hline Aylar & Mak. Sic. $\left({ }^{\circ} \mathrm{C}\right)$ & Min. S1c. $\left({ }^{\circ} \mathrm{C}\right)$ & Ort. Sic. $\left({ }^{\circ} \mathrm{C}\right)$ & Ort. Yağış (mm) & Nisbi Nem (\%) \\
\hline Eylül-1998 & 39,6 & 15,1 & 27,0 & 0,0 & 53,3 \\
\hline Ekim-1998 & 34,1 & 10,2 & 21,5 & 0,1 & 49,5 \\
\hline Kasım-1998 & 27,9 & 8,8 & 16,7 & 22,7 & 66,4 \\
\hline Aralık-1998 & 18,5 & 2,8 & 9,6 & 68,6 & 71,9 \\
\hline Ocak-1999 & 16,4 & 2,2 & 8,4 & 39,9 & 71,9 \\
\hline Şubat-1999 & 18,2 & $-3,2$ & 8,2 & 86,3 & 71,3 \\
\hline Mart-1999 & 23,4 & 2,0 & 11,5 & 43,3 & 64,0 \\
\hline Nisan-1999 & 32,0 & 6,3 & 16,6 & 58,1 & 63,3 \\
\hline Mayıs-1999 & 37,2 & 11,0 & 24,8 & 0,5 & 44,2 \\
\hline Haziran-1999 & 40,0 & 18,8 & 28,8 & 1,6 & 43,6 \\
\hline Temmuz-1999 & 43,2 & 21,5 & 32,5 & - & 39,7 \\
\hline Ağustos-1999 & 43,0 & 20,5 & 31,2 & 26,0 & 44,7 \\
\hline Eylül-1999 & 36,6 & 17,0 & 26,2 & - & 46,8 \\
\hline Ekim-1999 & 35,6 & 11,3 & 21,0 & 8,4 & 51,2 \\
\hline Kasım-1999 & 25,0 & 1,2 & 13,5 & 0,8 & 50,9 \\
\hline Aralık-1999 & 20,0 & 3,0 & 10,0 & 36,7 & 66,0 \\
\hline Ocak-2000 & 20,5 & $-2,4$ & 4,9 & 127,2 & 74,3 \\
\hline Şubat-2000 & 16,6 & $-1,5$ & 6,6 & 42,8 & 63,0 \\
\hline Mart-2000 & 25,5 & $-0,6$ & 10,3 & 31,5 & 55,2 \\
\hline Nisan-2000 & 29,6 & 6,1 & 17,8 & 18,3 & 56,8 \\
\hline May1s-2000 & 35,3 & 10,6 & 23,1 & 3,3 & 41,0 \\
\hline Eylül 1998 - & Ağustos 1999 & Toplamı & & 347,1 & \\
\hline Eylül 1999 - & Ağustos 2000 & Toplamı & & 269 & \\
\hline
\end{tabular}

\section{Kuadrat (Quadrat) Yöntemi}

Bu yöntemde; mera alanlarının incelenmesi için $1 \times 1 \mathrm{~m}$ boyutunda çerçeveler kullanılmıştır. Korunan alanlarda yapılan uygulamalara ait her bir parsel için 20 kare rasgele atılmıştır. Her kare içerisine giren bitkiler; buğdaygil, baklagil ve diğergiller olarak üç gruba ayrılmış bunlar ayrı kese kağıtlarında kurutulmuş olup, kurutulan bitkiler tartılarak, meranın verim potansiyeli ve ağırlığa göre botanik bileşimi saptanmıştır (Tükel, 1981).

\section{Incelenen Özellikler}

Kuru ot verimi: Korunan alanlardaki uygulamalarda her bir parsel için 20 kuadrat (Her bir kuadrat $1 \times 1=1 \mathrm{~m}^{2}$ alan) rastgele atılmış ve yeşil ot olarak biçildikten sonra, bu örnekler kese kağıtlarına konulup güneşte ağırlıkları sabitleşinceye kadar kurutulup kuru ot verimi $\mathrm{kg} / \mathrm{da}$ olarak hesaplanmıştır.

Mera durumu sinıflandırması: Araştırma sonucunda elde edilen kalitatif ve kantitatif değerlerden faydalanarak belirlenmiştir.

\section{Bulgular ve Tartışma}

Kuru Ot Verimi

Denemenin birinci yılında korunan+otlatılan alanlarda, ikinci yılında ise korunan+otlatılan ve uygulamalar, iki yıllık birleşik analizlerde de, yıl, korunan+otlatılan alanlar arasındaki farkın ve ayrıca yıl $\times$ korunan+otlatılan, yıl $\times$ uygulamalar arasındaki etkileşimlerin önemli olduğu saptanmıştır. 
Y1l $\times$ korunan-otlatılan alan ile y1l $\times$ uygulamalar arasındaki interaksiyonu etkileyen faktörlerin başında, farklı seviyelerdeki uygulamalarla (tohumlama, gübreleme ve sürüm) birlikte, birinci yıla oranla ikinci yılda daha az bir yağış düşmesi sonucu, verim değerlerinde meydana gelen dalgalanmalardan kaynaklanabilir. Otlatılan alanda birinci yılda yürütülen uygulamalar içerisinde, en yüksek kuru ot verimi $(53,70 \mathrm{~kg} / \mathrm{da})$ tohumlanan meradan, en düşük kuru ot verimi ise $(31,16 \mathrm{~kg} / \mathrm{da})$ ile doğal (kontrol) meradan elde edilmiştir. Korunan alanda birinci yılda yürütülen uygulamalar içerisinde, en yüksek kuru ot verimi $(199,71 \mathrm{~kg} / \mathrm{da})$ gübrelenen meradan, en düşük kuru ot verimi ise $(98,94 \mathrm{~kg} / \mathrm{da})$ ile doğal (kontrol) meradan elde edilmiştir.

Otlatılan alanda ikinci yılda yürütülen uygulamalar içerisinde, en yüksek kuru ot verimi $(45,49 \mathrm{~kg} / \mathrm{da})$ gübrelenen+tohumlanan meradan, en düşük kuru ot verimi ise $(11,64 \mathrm{~kg} / \mathrm{da})$ doğal(kontrol) meradan elde edilmiştir. Korunan alanda ikinci yılda yürütülen uygulamalar içerisinde, en yüksek kuru ot verimi $(142,88 \mathrm{~kg} / \mathrm{da})$ gübrelenen meradan, en düşük kuru ot verimi ise $(66,61$ $\mathrm{kg} / \mathrm{da})$ doğal(kontrol) meradan elde edilmiştir. İki yıllık ortalamalara göre; otlatılan alanda en yüksek kuru ot verimi $(47,98 \mathrm{~kg} / \mathrm{da})$ gübre+tohumlanan meradan, en düşük değer ise $(21,40 \mathrm{~kg} / \mathrm{da})$ ile doğal(kontrol) meradan elde edilmiştir. İki yıllık ortalamalara göre; korunan alanda en yüksek kuru ot verimi $171,29 \mathrm{~kg} / \mathrm{da}$ ile gübrelenen meradan, en düşük değer ise $82,77 \mathrm{~kg} / \mathrm{da}$ ile doğal(kontrol) meradan elde edilmiştir. İki yıllık ortalamalara göre, korunan + otlatılan alanlarda tüm uygulamalar 52,08 kg/da ile $108,90 \mathrm{~kg} / \mathrm{da}$ arasında değişim göstermiştir. İki yıllık ortalamalara göre, korunan + otlatılan alanlarda farklı üç grup oluşmuştur. Birinci yıldaki mera verimlerinin, ikinci yıla oranla yüksek olması, ikinci yılda mera bitkilerinin vejetatif gelişme dönemlerinde (Mart, Nisan) aylarının kurak geçmesi sonucu; ikinci yılda mera veriminin düşmesine neden olmuştur. $\mathrm{Bu}$ durum, çayır mera verimlerinin, yıldan yıla iklimdeki dalgalanmalara paralel olarak değişebileceğini bildiren bazı araştırıcıların bulgulariyla (Beetle, 1956), (Stoddart, 1955), (Tükel, 1981), (Y1lmaz, 1977) desteklenmektedir.

Korunan ve otlatılan alanlarda yapılan uygulamalardan elde edilen kuruot verimlerini inceleyecek olursak, korunan alanda gübrelenen, otlatılan alanda ise gübrelenen+tohumlanan alandan en yüksek verim alınırken, en düşük verim ise doğal(kontrol) meradan elde edilmiştir. $\mathrm{Bu}$ verimdeki farklılık ise yapılan uygulamalardan kaynaklanmaktadır.

Çizelge 3 Şanlıurfa ili Fatik dağları korunan ve otlatılan meralarında uygulanan değişik 1slah yöntemlerinden elde edilen ortalama kuru ot verimleri $(\mathrm{kg} / \mathrm{da})$

Table 3 Şanlurfa province Fatik mountains preserved and grazing pastures average dry grass yields obtained from different breeding methods $(\mathrm{kg} / \mathrm{da})$

\begin{tabular}{|c|c|c|c|}
\hline & \multicolumn{3}{|c|}{ 1. Y1l } \\
\hline Uygulamalar & Otlatılan Mera & Korunan Mera & Ortalama* \\
\hline Doğal (Kontrol) & 31,16 & 98,94 & $65,05^{\mathrm{b}}$ \\
\hline Gübreleme & 48,95 & 199,71 & $124,33^{\mathrm{a}}$ \\
\hline Tohumlama & 53,70 & 164,22 & $108,96^{\mathrm{a}}$ \\
\hline Gübreleme+ Tohumlama & 50,48 & 153,78 & $102,13^{\mathrm{ab}}$ \\
\hline \multirow{3}{*}{$\begin{array}{l}\text { Gübreleme }+ \text { Tohumlama }+ \text { Sürüm } \\
\text { Lsd }(\% 5)^{*}(\% 1)^{* *} \\
\text { Ortalama }\end{array}$} & 39,30 & 195,01 & $117,15^{\mathrm{a}}$ \\
\hline & \multicolumn{3}{|c|}{43,88} \\
\hline & \multicolumn{3}{|c|}{$162,33^{\mathrm{b}}$} \\
\hline \multicolumn{4}{|c|}{ 2. Y1l } \\
\hline Doğal (Kontrol) & 11,64 & 66,61 & $39,12^{\mathrm{c}}$ \\
\hline Gübreleme & 44,05 & 142,88 & $93,46^{\mathrm{a}}$ \\
\hline Tohumlama & 33,69 & 78,70 & $56,19^{\mathrm{bc}}$ \\
\hline Gübreleme+ Tohumlama & 45,49 & 105,86 & $75,68^{\mathrm{ab}}$ \\
\hline Gübreleme + Tohumlama + Sürüm & 38,66 & 139,77 & $89,22^{\mathrm{a}}$ \\
\hline $\operatorname{Lsd}(\% 5)^{*}(\% 1)^{* *}$ & \multicolumn{3}{|c|}{32,08} \\
\hline \multirow[t]{2}{*}{ Ortalama } & \multicolumn{3}{|c|}{$\begin{array}{c}52,00 \\
106,76^{\mathrm{b}}\end{array}$} \\
\hline & \multicolumn{3}{|c|}{ 1. ve 2. Yil } \\
\hline Doğal (Kontrol) & 21,40 & 82,77 & $52,08^{\mathrm{c}}$ \\
\hline Gübreleme & 46,50 & 171,29 & $108,90^{\mathrm{a}}$ \\
\hline Tohumlama & 43,69 & 121,46 & $82,58^{\mathrm{b}}$ \\
\hline Gübreleme+ Tohumlama & 47,98 & 129,82 & $88,90^{\mathrm{ab}}$ \\
\hline \multirow{3}{*}{$\begin{array}{l}\text { Gübreleme+ Tohumlama+Sürüm } \\
\text { EGF }(\% 5)^{*}(\% 1)^{* *} \\
\text { Ortalama }\end{array}$} & 38,98 & 167,39 & $103,18^{\mathrm{ab}}$ \\
\hline & \multicolumn{3}{|c|}{25,98} \\
\hline & $39,71^{\mathrm{a}}$ & $134,55^{\mathrm{b}}$ & \\
\hline
\end{tabular}

\section{Otlatılan Alan}

Üstten tohumlamada kullanılan bitki türlerini incelediğimizde Lolium perenne, Festuca rubra, Festuca ovina, Bromus inermis, Agropyron cristatum gibi, çok iyi bir tohum yatağı isteyen bitki türleri, mera alanı üzerinde yeterli bir toprak yapısı bulamaması yanında yıl içerisinde etkili ve düzenli bir yağışın düşmemesi sonucu çimlenemeden mera alanı üzerinden uzaklaşmalarıdır. Ayrıca üsten tohumlamada kullanılıp hayatlarını devam ettiren Onobrychis sativa, Medicago sativa, Poa pratensis gibi türler, vejetatif dönemde (Mart, Nisan, Mayıs aylarında) sıcaklıkların yükselmesi, yeterli yağışın düşmemesi ve yaz sıcaklarının çok yükselmesinden dolayı mera alanlarından uzaklaşmışlardır. 
Bunun sonucu olarak, bu bitkiler verim potansiyellerini tam olarak ortaya koyamamışlardır. $\mathrm{Bu}$ türlerden (Onobrychis sativa, Medicago sativa, Poa pratensis) ikinci yılın kurak geçmesi sonucu mera alanından uzaklaşmışlardır, $\mathrm{Bu}$ nedenle istenilen verim düzeyine ulaşılmamıştır. Ayrıca üsten tohumlamayla meraya ekilen tohumların merada uzun bir süre canlılıklarını sürdürebilmeleri için yıl içerisinde düzenli bir yağışın olması yanında mutlaka düzenli bir otlatmanın yapılması gerekmektedir (Dağdeviren, 1993), (Düzgüneş ve ark, 1965), (Lampeter, 1974), (Tarman, 1962).

\section{Korunan Alan}

İki yıllık ortalamalara göre; otlatılan düșük verimli $(21,40 \mathrm{~kg} / \mathrm{da})$ mera alanlarını yalnızca koruma alınmasıyla \%386 oranında bir verim $(82,77 \mathrm{~kg} / \mathrm{da})$ artışının sağlandığ saptanmıştır. Otlatılan mera alanlarını $(21,40 \mathrm{~kg} / \mathrm{da})$ hem koruma altına alıp hem de gübreleyerek \%800 oranında $(171,29)$ bir verim artışı olduğu saptanmıştır. Otlatılan mera alanların $1(21,40 \mathrm{~kg} / \mathrm{da})$ hem koruma altına alıp hem de tohumlayarak \%567 oranında $(121,46)$ bir verim artış1 olduğu saptanmıştır. Otlatılan mera alanlarında $(21,40$ $\mathrm{kg} / \mathrm{da}$ ) hem koruma hem de gübreleme-tohumlama yoluyla \%606 oranında $129,82 \mathrm{~kg} / \mathrm{da}$ ) bir verim artışı olduğu saptanmıştır. Otlatılan mera alanlarını $(21,40 \mathrm{~kg} / \mathrm{da})$ hem koruma hem de gübrelemek-tohumlama-sürüm suretiyle $(167,39 \mathrm{~kg} / \mathrm{da}) \% 782$ oranında bir verim artışı olduğu saptanmıştır.

Bölge meralarının ıslahında en etkili ve en ekonomik yol mera alanlarını koruma altına almanın yanında uygun bir gübreleme yöntemi ile düzenli bir otlatma amenajmanının uygulanmasından geçmektedir. $\mathrm{Bu}$ bulgularımız bazı araştırıcıların bulguları ile uyum içerisindedir (Büyükburç, 1982).

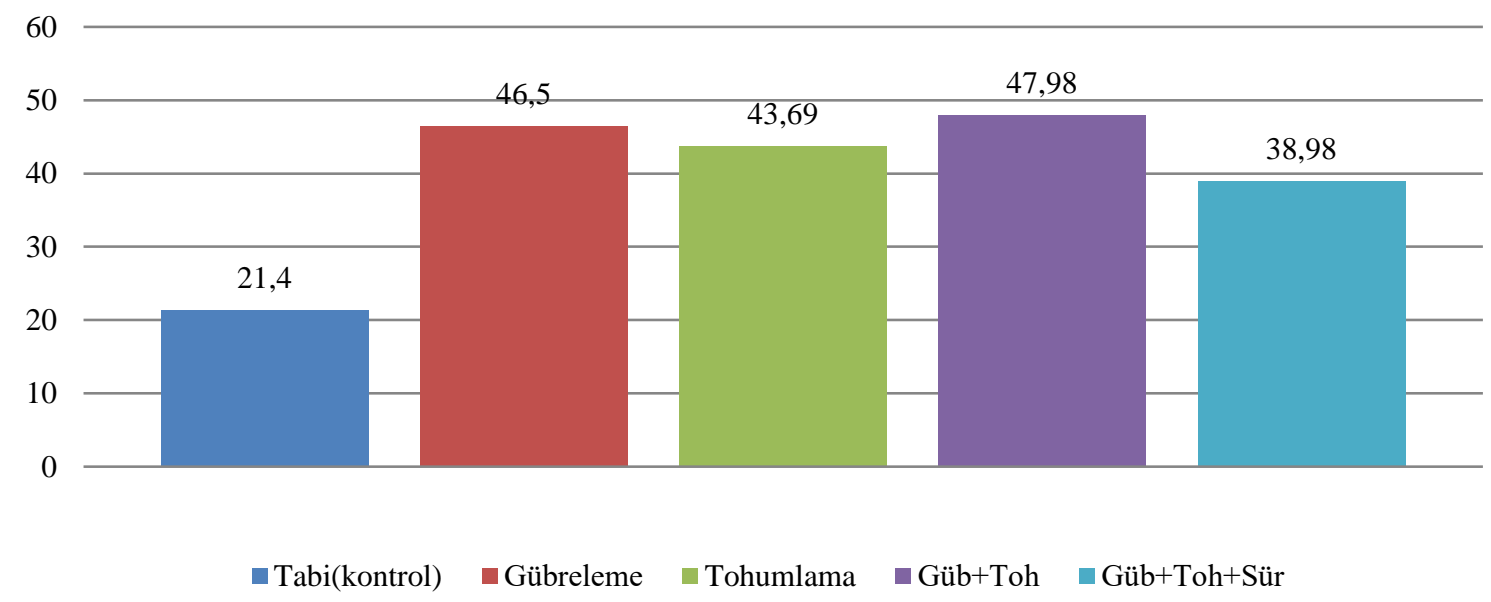

Grafik 1 İki Yıllık Ortalamalara Göre Otlatılan mer’a alanlarında Yapılan Uygulamalardan Elde Edilen Kuru Ot Verimleri (kg/da)

Figure 1 Pasture Based on Two-Year Averages Obtained from Pasture Structured Applications Dry Weed Yields (kg/da)

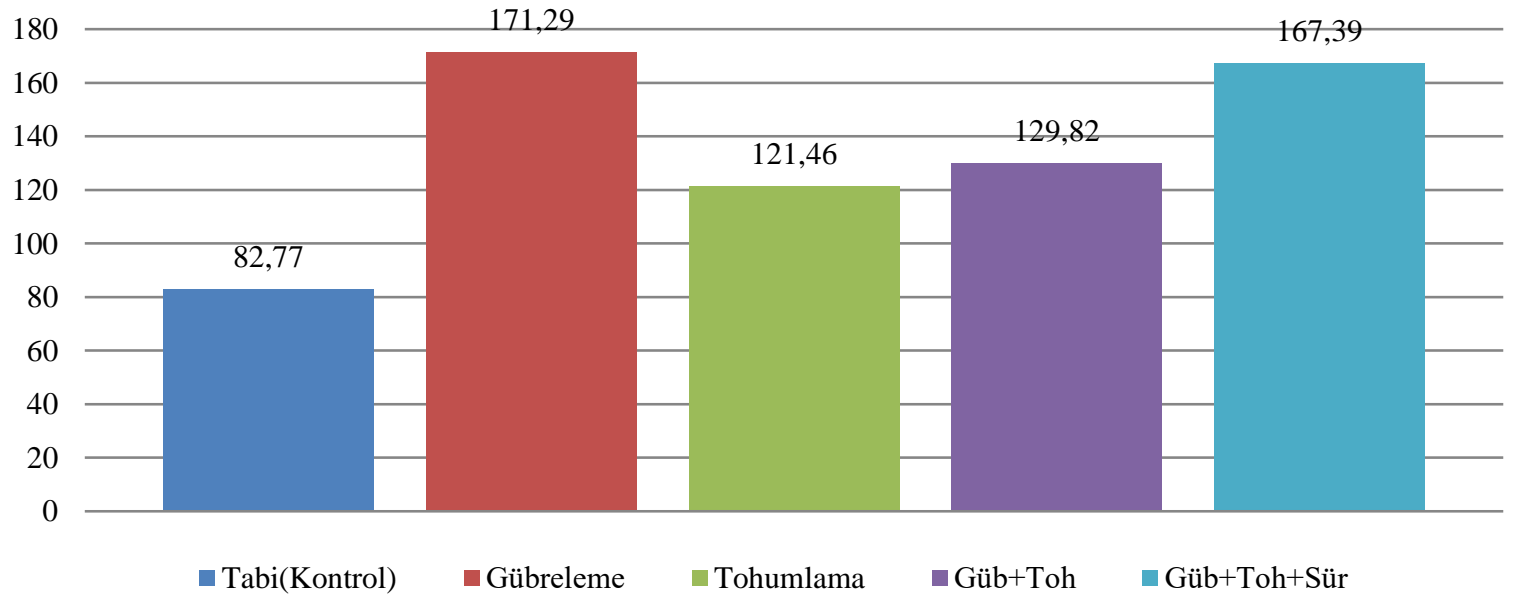

Grafik 2 İki Yıllık Ortalamalara Göre Korunan Mera Alanlarında Yapılan Uygulamalardan Elde Edilen Kuru Ot Verimleri (kg/da).

Figure 2 Obtained from Applications Made in Protected Pasture Areas According to Two-Year Averages Dry weed Yields $(\mathrm{kg} / \mathrm{da})$ 
Çizelge 4 Şanlıurfa ili Fatik dağları otlatılan meralarında saptanan bitki türlerinin kıymetlendirme ve kalite dereceleri

Table 4 Valuation and quality degrees of plant species in grazing pastures of Fatik mountains in Şanlurfa province

\begin{tabular}{|c|c|c|c|}
\hline Bitki Türleri & $\begin{array}{c}\text { Kiymetlendirme } \\
\text { Derecesi }\end{array}$ & $\begin{array}{c}\text { Otlatılan Alan Kalite } \\
\text { Dereceleri }\end{array}$ & $\begin{array}{c}\text { Korunan Alan Kalite } \\
\text { Dereceleri }\end{array}$ \\
\hline Trifolium campestra & 6 & 3,78 & 8,6 \\
\hline Trigonella kotschyi & 4 & 8 & 5,4 \\
\hline Bromus tectorum & 1 & 0,52 & 3,47 \\
\hline Aegilops ovata & 3 & 7,56 & 4,62 \\
\hline Poa bulbosa & 4 & 100,72 & 115,92 \\
\hline Avena fatua & 4 & 1,68 & 20,84 \\
\hline Bromus sp & 2 & 1,04 & 1,92 \\
\hline Torilis microcarpa & 0 & 0 & - \\
\hline Trifolium lappaceum & 4 & 37,48 & 4,6 \\
\hline Trifolium stellatum & 4 & 16 & 17 \\
\hline Alopecurus pratensis & 7 & 136,43 & 49,98 \\
\hline Acantus siriacus & 0 & 0 & 0 \\
\hline Hippocrepis unisiliquosa & 4 & 11,8 & 2,28 \\
\hline Bromus sp, & 1 & 1,26 & 6,16 \\
\hline Bromus squarrosus & 3 & 3,15 & 9,27 \\
\hline Vicia sp, & 4 & 4,2 & - \\
\hline Trifolium globosum & 4 & 8 & 2,28 \\
\hline Cirsium sp, & 0 & 0 & - \\
\hline Echinaria capitata & 1 & 0,31 & - \\
\hline Cirsium arvense & 0 & 0 & 0 \\
\hline Salvia syriaca & 0 & 0 & 0 \\
\hline Vulpia dannthonii & 1 & 0,63 & 1,54 \\
\hline Linum sp, & 0 & 0 & 0 \\
\hline Medicago coronata & 5 & 3,15 & 8,1 \\
\hline Cirsium sp, & 0 & 0 & 0 \\
\hline Trifolium scabrum & 4 & 1,24 & - \\
\hline Scorpiurus muricatus & 3 & 0,63 & 4,62 \\
\hline Achillea meliformis & 0 & 0 & - \\
\hline Crupina vulgaris & 0 & 0 & 0 \\
\hline Stellaria media & 0 & 0 & 0 \\
\hline Valerianella versicaria & 0 & 0 & 0 \\
\hline Thlaspi arvense & 0 & 0 & 0 \\
\hline Medicago truncatula & 6 & 1,86 & 10,38 \\
\hline Bromus erectus & 5 & 1,55 & 4,62 \\
\hline Medicago minima & 5 & 1,55 & 15,45 \\
\hline Scandix pecten-veneris & 0 & 0 & - \\
\hline Dactylis glomerata & 7 & 1,47 & 0,56 \\
\hline Trifolium tomentosum & - & 2,51 & 15,06 \\
\hline Coronilla scorpioides & - & 0,19 & 1,14 \\
\hline Hordeum bulbosum & - & 5,79 & 28,95 \\
\hline Geranium molle & - & 2,51 & 2,51 \\
\hline Cynodon dactylon & - & 0,77 & 3,08 \\
\hline Salvia sp, & - & 1,73 & 0 \\
\hline Papaver rhoeas & - & 2,31 & 0 \\
\hline Trifolium fragiferum & - & 1,73 & 10,38 \\
\hline Genel Toplam & & 354,01 & 358,73 \\
\hline Kalite Derecesi & & 3,54 & 3,58 \\
\hline
\end{tabular}

Mera Durumu Sinıflandırılmast

Çizelge 4'te görüldüğü gibi, otlatılan alanda en yüksek bitki ile kaplı alana sahip bitkiler sirasiyla Poa bulbosa \%11,95, Alopecurus pratensis \%9,25, Trifolium lappaceum \%4,45, Torilis microcarpa \%3,35 türleri yer almaktadır. Taş, çakıl ve toprak alanın \%52,5 olması, bu bölge meralarında aşırı bir otlatma ve erozyon olayının önemli bir göstergesidir.

Korunan alanda en yüksek bitki ile kaplı alana sahip bitkiler sirasıly Poa bulbosa \%15,00, Trifolium stellatum
$\% 4,40$, Alopecurus pratensis \%3,80 Thlaspi arvense $\% 3,70$ türleri yer almaktadır. Otlatılan alan iki yıllık koruma altına alınarak bitkiyle kaplı alan değerleri \%47,5'den, \%52,65'e yükselmiştir. Amerika'da da Parker (1954), toprak yüzeyinin \%51 çıplak olması halinde çok şiddetli ve tehlikeli bir erozyonla karşı karşıya bulunduğunu bildirmektedir. Orta Anadolu'da yapılan araştırmalarda bitki örtüsünün \%15-20, çıplak toprak yüzeyinin \%80-85 olmasını erozyon tehlikesinin sınırları olduğu belirtmektedir. 
Tarman (1968), Türkiye'de özellikle Orta ve Güneydoğu Anadolu bölgesindeki meraların bitki örtüsünün çok seyrekleşmesi sonucunda su ve rüzgâr erozyonunun yalnız mera alanlarını değil, çevresindeki tarımı yapılan alanları da tehdit ettiğini bildirmektedir. Çizelge 4'te görüldüğü gibi; otlatılan meralardaki en yüksek botanik bileşim değerlerine sahip bitkiler sırasıyla Poa bulbosa \%25,18, Alopecurus pratensis \%19,49, Trifolium lappaceum \%9,37, Torilis microcarpa \%7,06 türleridir. Korunan meralardaki ise en yüksek botanik kompozisyon değerleri gösteren türler ise sirasıly Poa bulbosa \%28,98, Alopecurus pratensis \%7,14, Hordeum bulbosum \%5,79, Avena fatua \%5,21 türleridir. Mera araştırma alanı koruma altına alınmasıyla tohumla üreyen, Hordeum bulbosum, Avena fatua gibi türler mera alanı üzerinde çoğalmışlardır.

Çizelge 4'te görüldüğü gibi; birinci yıl içerisinde koruma altına alınan alanda yapılan transekt ölçümlerine göre baklagillerin oranı \%51 olarak saptanmıştır. Bu mera araştırma alanı iki yıl koruma altına alınmasına karşın, baklağiller oranı \%18,35 kadar düşmüştür. Bunun en önemli nedenleri, ikinci yılın kurak geçmesi sonucu, doğal vejetasyondaki baklagil türleri gelişimlerini yeterince sürdürememişlerdir. Ancak, buğdaygiller baklagillere oranla kuraklığa daha fazla dayanıklı türler olduğu için, biki örtüsü içerisinde yaşamlarını sürdürme olanağı bulmasından dolayı, bitki bileşimi içerisindeki oranları ise artmıştır.

Çizelge 4'te görüldüğü gibi, otlatılan meralardaki en yüksek tekerür değerlerine sahip bitkiler sirasıyla Poa bulbosa \%100, Alopecurus pratensis \%100, Trifolium lappaceum \%86, Torilis microcarpa \%80 türleridir. Korunan mera alanlarında ise en yüksek tekerür değerlerini gösteren bitkiler sirasıyla Poa bulbosa \%86, Alopecurus pratensis \%80, Trifolium stellatum \%66, Bromus tectorum $\% 53$ türleridir.

Çizelge 5 Mera Durumu Iskalası (Uluocak 1978) Table 5 Pasture Status Scale (Uluocak 1978)

\begin{tabular}{c|l}
\hline Kalite Derecesi & Mera Durumu \\
\hline 8,1 & Çok iyi \\
$6,1-8$ & İyi \\
$4,1-6$ & Orta \\
$2,1-4$ & Zayıf \\
$0,0-2$ & Çok Zayıf \\
\hline
\end{tabular}

Çizelge 5'te Şanlıurfa ili Fatik dağları otlatılan ve korunan meralarında saptanan kalite derecesi 3,54 ve 3,58 olup, Çizelge 5'te mera durumu 1skalasna göre, karşılaştırdığımızda zayıf mera grubuna girmektedir. Bundan da anlaşılacağı gibi, koruma altına alınan mera alanlarında, meranın kalite derecesi ve durumu üzerinde olumlu bir etki yapmamışsa da bu konuda beklenen olumlu gelişmelerin daha uzun bir zaman içerisinde ortaya çıkacağı sonucuna varılmıştır, $\mathrm{Bu}$ değerlerimiz bazı araştırmacıların (Büyükburç, 1982) bulgularıyla uyum içerisindedir.

\section{Sonuç}

Ülkemiz ve bölgemiz çayır-mera alanları asırlardan beri sürekli olarak, ağır ve erken otlatılmakta ve bunun sonucu olarak bugün İç Anadolu, Güneydoğu Anadolu ve geçit bölgelerimizde meraların kuru ot verimleri yer yer $10-20 \mathrm{~kg} /$ dekara kadar düşmüş bulunmaktadır. Güneydoğu Anadolu Bölgesinde Şanlıurfa ili dağları, doğal meraları uzun zamandan beri süre gelen düzensiz otlatma nedeniyle ileri derecede bozulmuş ve verimleri azalmış durumdadır. $\mathrm{Bu}$ meraların 1slah edilerek yeniden verimli hale getirilebilmeleri için herşeyden önce düzenli bir otlatma siteminin uygulanması gerekmektedir. Mera 1slahı için uygulanacak sistemler arasında, belli dönemlerde mera vejetasyonun otlatmadan korunarak dinlendirilmesini sağlayan sistemler özel bir önem taşımaktadır. Islah metodlarından doğal tohumlama desteklenerek teşvik edilerek mera vejetasyonun geliştirilmesi sağlanmalıdır.

Yarıkurak ve kurak bölgelerde otlatmanın düzenlenmesi ve mera vejetasyonun dinlendirilmesiyle 1slahı uzun zaman alacağından, bu işlemi gübreleme ve 1slah yöntemleriyle hızlandırılmalıdır. $\mathrm{Bu}$ amaçla, bölge dağları doğal meraalarında aşırı derecede otlatılmış bu mera alanları iki yıl boyunca koruma altına alınarak farklı sslah yöntemleri (koruma, gübreleme, tohumlama, gübreleme+tohumlama, gübreleme+tohumlama+sürüm) uygulanmıştır. Sonuç olarak bölge meralarının ıslahında en etkili ve en ekonomik yolun, mera alanlarını koruma altına almak ve uygun bir gübreleme yöntemi ile düzenli bir otlatma amenajmanı uygulamak olduğu görülmektedir.

\section{Kaynaklar}

Anonim. 1998. Meteoroloji Bölge Müdürlüğü Ortalama ve Ekstrem Kiymetler Meteoroloji Bülteni (1920-1990), Şanlıurfa

Anonim. 1998. Aylık Meteoroloji Bültenleri, Şanlıurfa

Anonim. 1999. Aylık Meteoroloji Bültenleri, Şanlıurfa

Anonim. 2000. Aylık Meteoroloji Bültenleri, Şanlıurfa

Bakır Ö, Açıkgöz E. 1976. Yurdumuzda Yem Bitkileri ÇayırMera Tarımının Bugünkü Durumu, Geliştirme Olanakları ve $\mathrm{Bu}$ Konuda Yapılan Çalışmalar, Ankara Çayır-Mera ve Zootekni Araştırma. Enst, Yay, No:61 Çayır ve Meralar (Türkiye'nin Çevre Sorunları) Türkiye Çevre Sorunları Vakfı Yayınları, (1981).

Büyükburç U. 1982. Ankara İli Yavrucak Köyü Meralarının Gübreleme ve Dinlendirme Yoluyla Islah Olanakları Üzerinde Araştırma, Genel Müdürlüğü Çayır Mera ve Zootekni Araştırma Enstitüsü Yayın No:78 Pp:23-24 Ankara

Conard EC, Bakır Ö. 1957. Improvement of Pastures and Meadows, (Ankara Ünv, Zir, Fak Ders Notu).

Çalık A, 2018, With Different Fertilization Mixed Growing Plant Total Green Weed Yield And Green Weed In Triticale, Vetch Of Rate Plant With Size Relationship, 1. Uluslararasi Gap Matematik-Mühendislik- Fen ve Sağlık Bilimleri Kongresi, 4-7 Ekim 2018.

Dağdeviren İ, Erdoğan İ. 1993. GAP Bölgesi Şanlıurfa Yöresinde Bazı Mera İyileştirme Yöntemlerinin Toprak ve $\mathrm{Su}$ Korunumuna Etkisinin Saptanmas1, Köy Hizmetleri Araştırma Enstitüsü Yayınları, Şanlıurfa.

Düzgüneş O, Bakır Ö, Aksoy S, Akyüz Ö, Alınoğlu N. 1965, Meralarımızla İlgili Problemler ve Çözüm Yolları, TMMOB Ziraat Mühendisleri Odası Yayınları, Sira No: 21, Mars Matbaası, Ankara, $11 \mathrm{~S}$.

Elçi Ş, Açıkgöz E. 1980. Sentetik Varyete Elde Etmek Amacıyla Seçilmiş Yerli Polikros Döller Ve Yabancı Kılçıksız Brom (Bromus Inermis Leyss, ) Çeşitlerinin Kıraçta Ot Verimi İle Yabancı Kılçıksız Brom (Bromus Inermis Leyss) Çeşitlerinin Kıraçta Ot Verimi İle Bazı Morfolojik Özellikleri Tubitak Toag Kurak Bölge Tarla Bitkileri Araştırma Ünitesi Proje No: 14 
Gençkan MS. 1985. Çayır Mera Kültürü Amenajman Islahı, Ege Üni, Zir, Fak, Yay: 483 S, 378 Bornova/İzmir

Parker KW. 1954. Application of Ecology in The Determination Of Range Condition And Trend, Journal of Range Management, Vol:7, No:1, 14-22

Stoddart LA, Smith AD. 1955, Range M Anagem Ent, Mc Graw - Hill Book Inc, N, Y.

Tarman Ö. 1962. Bölgesel Ekonomik Özellikler Üzerine Etkileri ve Toprak Muhafaza. Ankara Üniversitesi Ziraat Fakültesi Yıllığı, Pp, 26-28, Ankara.

Tarman Ö. 1968, Yem Bitkileri, Çayır ve Mera Kültürü ve Genel Prensipleri, Ankara Üniversitesi, Ziraat Fakültesi Yayınları, No: 464, Ankara.

Tükel T, Tansı V, Polat T, Hasar E. 1992. Taurus Mountain of Project In Turkey, Field Crops And Grazing Land Studies, Farm Research Management Program Annual Report For 1991, Icarda, P, O, Box 5466, Aleppo, Syria, (1992).
Tükel T. 1981. Ulukışla'da Korunan Tipik Bir Step Dağ Merası ile Eş Orta Malı Meraların Bitki Örtüsü ve Verim Güçlerinin Saptanması Üzerine Araştırmalar, Doçentlik Tezi, ÇÜ, Ziraat Fakültesi.

Tükel TK, Hatipoğlu R.1987, Çukurova Taban Arazilerimde Bazı Tek Yıllık Baklagil + Tahıl Karışımlarının Farklı Biçim Zamanlarındaki Yem Üretim Potansiyeli Üzerine Bir Araştırma, Doğa Tübitak Tarım ve Ormancılık Dergisi, 2(3): 558-566.

Uluocak N. 1978, Kırklareli Yöresi Ormaniçi Mera Vejetasyonunun Nitelikleri ve Bazı Kantitatif Analizleri, ÎÜ, Orman Fak, Yayın No, 2107 - 253.

Yılmaz T. 1977. Konya İli Sorunlu Alanlarında Olușan Meraların Bitki Örtüsü Üzerinde Araştırmalar, Tarım Bakanlığı Toprak Su Gn, Müd, Konya Bölge Toprak Su Araştırma Enstitüsü Yayınları, Genel Yayın No: 46, Raporlar Serisi No:32, Konya. 